\title{
Revisão Bibliométrica sobre Economia Criativa em Periódicos Nacionais entre 2008 a 2018
}

\author{
Bibliometric Review of Creative Economy in National Journals from 2008 to 2018
}

\author{
Emmanuelle Lopes de Almeida ${ }^{1}$ \\ Pâmela Karolina Dias ${ }^{2}$
}

\begin{abstract}
Resumo
O presente estudo objetivou entender como os pesquisadores brasileiros, no período entre 2008 a 2018, compreenderam e definiram o conceito de Economia Criativa em seus respectivos estudos. Para isso, este estudo fez uso da pesquisa bibliométrica e realizou um levantamento nos bancos de dados da Scielo, Spell e Periódico CAPES, objetivando compreender (a) quais revistas estavam publicando esses artigos, (b) qual a estratificação Qualis CAPES dessas revistas, (c) quais foram os anos que se concentraram as publicações, (d) quais os principais autores abordados na definição de Economia Criativa, (e) quais as áreas das revistas, bem como (f) a localidade e (g) as palavras-chave trazidas pelos artigos analisados. Observou-se, a partir da análise dos doze artigos selecionados, mediante os critérios preestabelecidos, que a autoria dos artigos analisados é de maioria produzida por homens, que a referência mais utilizada acerca do conceito de Economia Criativa é de uma dada pesquisadora e que os estudos predominam na região Sudeste. Conclui-se também que o conceito de Economia Criativa, nos textos analisados, concentra-se nos seguintes aspectos: desenvolvimento, cultura, criatividade e indústrias criativas, assim como a maioria dos estudos analisados trabalham a concepção de Economia Criativa relacionada à criatividade.
\end{abstract}

Palavras-chaves: Economia criativa; Indústria criativa; Serviços criativos; Revisão bibliométrica.

\begin{abstract}
The present study aimed to understand how Brazilian researchers, from 2008 to 2018, understood and defined the concept of the Creative Economy in their respective studies. For this, this study used bibliometric research and a survey in the databases of Scielo, Spell, and CAPES periodicals, aiming to understand (a) the journals that published these articles, (b) the Qualis CAPES stratification of these journals, (c) the years of these publications, (d) the main authors approached in the definition of the Creative Economy, (e) the magazine's areas, as well as (f) the locality and (g) keywords used in the articles analyzed. From the analysis of the twelve articles selected, according to the preestablished criteria, it was observed that the authorship is mostly made by men, the most used reference about the Creative Economy concept is from a specific researcher, and the predominate studies are from the southeastern region. It is concluded that the concept of the Creative Economy, in the analyzed texts, focuses on three aspects: development, culture, creativity, and creative industries, as well as most studies work on the Idea of the Creative Economy related to creativity.
\end{abstract}

Keywords: Creative economy; Creative industry; Creative services; Bibliometric review. da Violência contra a Mulher Elma Novaes (NUGEN - ASCES) e graduanda em Direito (ASCES-UNITA). 


\section{INTRODUÇÃO}

Inicialmente, convém ressaltar que a economia na atualidade é algo que se encontra em constante processo de reestruturação de sua produção. Por isso, essa área ainda experimenta grandes influências advindas, por vezes, da globalização, do aumento das especificações dos clientes com relação a determinados produtos ou serviços e também da crescente excitação da concorrência a nível global (JULIEN, 2010; CASTELLS, 2010; HARVEY, 2012; SILVA, 2014).

Nesse contexto, a Economia Criativa (EC) se estruturou como um recurso onde a criatividade, a aprendizagem, 0 conhecimento e a comunicação se destacam como importantes meios produtivos e estratégicos para as organizações (PIRES; ALBAGLI, 2012; ALMEIDA; TEIXEIRA, 2016). Mesmo que no Brasil o seu conceito ainda não disponha de fronteiras muito claras para individualizá-la em relação às outras variedades econômicas como a economia cultural ou a economia do conhecimento, por exemplo. Aliás, esse termo ainda apresenta significados e caracterizações, que se alteram conforme a região onde se localiza (SERRA; FERNANDEZ, 2014; OLIVEIRA; ARAÚJO; SILVA, 2013).

Acompanhando essas perspectivas, o Relatório de Economia Criativa (2010) ainda acrescenta que não dá para se ter uma definição clara para criatividade, visto que ela reúne diversas esferas da sociedade. No entanto, isso não impede a sua articulação como ponte entre empreendimentos humanos (UNCTAD, 2010). Consequentemente, também não impediu que ela fosse utilizada como um meio de obtenção de renda.

Por esse motivo, ao longo dos anos, ela exerceu consideráveis impactos no PIB (Produto Interno Bruto) brasileiro. Conforme dados do Sistema Firjan (2016), esses impactos ocorreram de maneira mais significativa em 2015 , fazendo a produção saltar de $2,56 \%$ para $2,64 \%$, gerando $\mathrm{R} \$ 155,6$ bilhões de reais para a economia de todo país. No mercado formal de trabalho do respectivo ano, por exemplo, ela gerou um crescimento no número de profissionais ativos, totalizando 851,2 mil pessoas atuando em indústrias criativas. Em 2017, apesar do pequeno regresso de seus valores de 2,64\% para 2,61\%, essa área ainda conseguiu se manter como responsável por uma geração de valor expressiva do PIB brasileiro totalizando R\$ 171,5 bilhões de reais. Sendo que em Pernambuco, particularmente, o PIB criativo no Estado foi de 1,9\%, aproximadamente (FIRJAN, 2019).

Além disso, a EC ainda trata-se de "[...] um novo campo de estudos, no qual emergem questões como o papel da criatividade, a natureza dos produtos criativos e suas cadeias produtivas, [...] e a própria relação entre tecnologia e arte" (SERRA; FERNANDEZ, 2014, p. 361). Algo que proporciona amplos caminhos para pesquisas nesse meio e, consequentemente, para pesquisas como essa, pois não se procura apenas observar conceitos, mas possibilitar a análise de mudanças através da diversidade de concepções existentes sobre a área.

Diante disso adveio o porquê de se analisar o conceito de Economia Criativa. Ademais por se tratar de campo de estudo recente e por não possuir uma fronteira clara do que vem a ser a Economia Criativa, já que seu conceito ainda se mescla com outros segmentos econômicos, conforme citam Serra, Fernandez (2014), Oliveira, Araújo e Silva (2013). Assim, certos saberes já existentes sobre o assunto podem acabar sendo suscetíveis de serem perdidos; relegando uma diversidade de informações à confusão e/ou ao esquecimento.

Além disso, em torno dessa temática ainda existem inúmeras questões teóricas que carecem de aprofundamento, bem como questões divergentes e/ou inconsistentes, que novamente evidenciam que este ainda se trata de um campo recente de estudos e repleto de pontos obscuros (SERRA; FERNANDEZ, 2014); tornando relevante a execução da presente pesquisa, também com os métodos e instrumentos escolhidos, visto que se apresenta como o caminho mais adequado para o alcance de seus objetivos.

Nesse sentido, essa pesquisa se justifica e contribui: (a) pela necessidade de se fazer um levantamento sobre a temática, visto que é um campo de estudos recentes e com muitas (in)conclusões em relação a sua definição, conforme também observado por Marçal e Santos (2018) e Serra e Fernandez (2014), e, portanto, existe uma lacuna teórica a ser atendida, corroborando com a crítica feita por Oliveira et al. (2016, p. 2977) ao afirmarem que "a Economia Criativa, tem sido pouco explorada em pesquisas acadêmicas"; (b) porque trabalha com uma diversidade de perspectivas e saberes a partir da pesquisa bibliométrica, com o objetivo de contribuir para discussão e viabilizar pontes de convergências sobre a produção de conhecimento acadêmico - e como a temática não entrou em consonância sobre a EC, mas no cotidiano a Economia Criativa já é algo tangível, principalmente no que se refere ao PIB, já que isso se sucedeu porque primeiro a EC acontece no campo político e econômico e depois no campo das universidades (SILVA; VIEIRA; FRANCO, 2019) -, apresentando-se como urgente pesquisas como essa; (c) por ser de grande relevância para outros pesquisadores da área.

Portanto, levando-se em consideração esses aspectos, a pergunta que orienta essa pesquisa é: de que maneira conceitos sobre a Economia Criativa vêm sendo abordados e compreendidos no período entre 2008 a 2018 no Brasil? Ou seja, de que maneira é possível reunir dados suficientes a respeito dos conceitos existentes sobre Economia Criativa entre 2008 a 2018, por meio de uma revisão bibliométrica de seus conceitos através da produção acadêmica nacional (indexados nos repositórios da Scielo, Spell e Periódico CAPES), mas com o intuito de auxiliar a compreensão coletiva sobre esse conceito?

O período escolhido entre 2008 a 2018 se justifica devido ao momento político e cultural no qual o Brasil se encontrava e que, de qualquer modo, impacta direta ou indiretamente na Economia Criativa e demais segmentos econômicos e empreendimentos nacionais. Desse modo, desde 2016, sob a gestão do governo Temer (2016-2018), 
o Ministério da Cultura (MinC) passou por múltiplas mudanças, inclusive foi extinto em um primeiro momento, depois redirecionado para o Ministério da Educação (MEC), e retornando posteriormente. Porém, essas mudanças não se findaram em 2019, durante a gestão do governo Bolsonaro, mas a partir de 2019 o MinC foi novamente extinto e criada uma secretaria especial da cultura que pertence ao Ministério da Cidadania (COIMBRA; MORAIS, 2019).

Assim, a extinção do MinC, em 2019, e as consequências disso, apontam para falta de prioridade que a cultura recebe neste país (MARÇAL; SANTOS, 2018), o que inclui também a EC. Por isso, o intervalo entre 2008 a 2018 tornase um período mais consistente para observar as produções acadêmicas sobre o tema, visto que a existência do MinC reflete em incentivos a partir de editais tanto à cultura quanto para pesquisas relacionadas também à Economia Criativa.

Considerando que a análise de temas como esse é voltada principalmente para a diversidade de saberes e organizações existentes dentro do mercado nacional, são objetivos desta pesquisa: (a) descrever os principais conceitos e/ou termos-chave e/ou palavras-chave atribuídas nos estudos analisados sobre o que os seus/suas pesquisadores(as) percebem e/ou compreendem enquanto Economia Criativa; (b) pontuar possíveis convergências e/ou divergências acerca das concepções existentes sobre EC; bem como (c) categorizar, ainda que de forma livre, os principais segmentos e/ou áreas que tenham sido atribuídos ao conceito de EC nesse processo; no intuito principal de (d) se aproximar do que é o conceito de Economia Criativa no meio acadêmico nacional.

Este trabalho, então, tem sua fundamentação teórica abordando os seguintes tópicos: percursos históricos da Economia Criativa, Economia Criativa e outras variedades econômicas e indústrias, bens e serviços criativos; na sequência procedimento metodológico; seguido pela análise dos artigos selecionados com base nos critérios predefinidos; e, por fim, a conclusão.

\section{FUNDAMENTAÇÃO TEÓRICA}

\subsection{Percursos históricos da economia criativa}

Factualmente, a Economia Criativa já era experienciada no exterior desde a década de 1990 sendo tratada apenas como um setor específico da sociedade. No ano de 1994, entretanto, passou a ser reconhecido mediante o conceito de Creative Nation e, dessa forma, o termo Economia Criativa, especificamente, só veio a se estabelecer efetivamente em 2001, após aparecer em uma capa da revista Business Week, sob o título de Creative Economythe 21 century corporation (MIGUEZ; NUSSBAUMER, 2007); e também conforme dados da Conferência das Nações Unidas sobre Comércio e Desenvolvimento (UNCTAD) (2010) após menção no livro do autor John Howkins do mesmo ano, intitulado The creative economy: how people make Money from ideas (HOWKINS, 2001).

Nessas circunstâncias, a economia nacional que outrora era baseada apenas no uso intensivo da mão de obra humana acabou cedendo espaço, gradualmente, para esse outro segmento moldado na criatividade e na troca de conhecimentos (MIGUEZ, 2007; BENDASSOLLI et al., 2009; JESUS, 2017); e desse modo também recebeu influências das novas tecnologias da informação e comunicação, pois o baixo custo ocasionado por elas proporcionou novas oportunidades para ampliar um mercado extremamente ávido por novidades (HOWKINS, 2001; NICOLACI-DA-COSTA, 2014).

Por esse motivo, em 2010 a UNCTAD também a adotou como sendo [...] "um conceito em evolução baseado em ativos criativos que potencialmente geram crescimento e desenvolvimento econômico" (UNCTAD, 2010, p. 10). Desde então, o conceito de Economia Criativa perpassou vários modelos e interpretações, não existindo uma única forma de defini-lo, mesmo este sendo constantemente associado, na contemporaneidade, à criatividade, tecnologia, cultura e economia. Atualmente essa temática se encontra entre os setores mais dinâmicos da economia internacional, o que lhe possibilita uma relação com outras variedades econômicas e também com a criação de oportunidades que permitam o crescimento de países em desenvolvimento econômico (UNCTAD, 2018, tradução nossa).

No Brasil, "o tema economia criativa aparece em 2004, na XI Conferência das Nações Unidas sobre Comércio e Desenvolvimento (UNCTAD), em um painel voltado às indústrias criativas nos países em desenvolvimento" (OLIVEIRA et al., 2016, p. 2969). Em 2011 a Economia Criativa ganha espaço em políticas públicas quando o MinC passou a ter uma secretaria destinada aos interesses políticos e econômicos da EC, recebendo o nome de Secretaria da Economia Criativa (SEC) e, posteriormente, sendo criado o Plano de Gestão da Economia Criativa da SEC com orientações e diretrizes para os principais agentes/atores da EC (SILVA; VIEIRA; FRANCO, 2019).

Este plano era baseado em quatro pilares: sustentabilidade, inovação, inclusão social e diversidade cultural. É importante contextualizar que a SEC aconteceu durante o governo de Dilma Rousseff; informação relevante para entender o surgimento das primeiras ações governamentais sobre a EC no país (MARCHI, 2013); assim como para evidenciar em que momento a EC começou a ganhar destaque e incentivos governamentais, se tornando relevante nacionalmente.

Desse modo, por ser algo tão abrangente, esse conceito será analisado com relação a outros setores mais adiante, pois, se fazendo um comparativo breve com outras áreas econômicas, será possível compreender suas especificidades e singularidades. 


\subsection{Economia criativa e outras variedades econômicas}

Existe uma linha tênue entre as diversas economias presentes em sociedade. Isso porque as atividades, bens ou serviços que compõem essas áreas possuem dupla natureza, ou seja, tanto atuam de maneira econômica como de maneira cultural (MACHADO, 2009; CARVALHAL; MUZZIO, 2015). É por essa razão, que ocorrem associações conceituais entre áreas tão diversas. No entanto, isso não impede que elas possuam suas próprias singularidades, uma vez que contemplam muitos saberes.

Desse modo, é possível observar que ao ser percebido como sendo o conjunto de atividades que dependem da criatividade para a geração de bens e serviços, a EC costuma ser qualificada no país como sendo tão distinta e ao mesmo tempo tão próxima de áreas como a Economia da Cultura. Principalmente por estabelecer uma extensa dinâmica entre atributos que envolvem aspectos econômicos, tecnológicos, socioculturais e de propriedade intelectual, que se correspondem em uma mesma perspectiva (HOWKINS, 2001; OLIVEIRA, ARAÚJO, SILVA, 2013).

Nesse contexto, apesar da Economia da Cultura também interagir com a tecnologia e a propriedade intelectual, não tem como foco um viés político, nem a geração de valor econômico; voltando-se, portanto, para uma abordagem mais analítica do que descritiva das suas relações (HERRMANN-PILATH, 2011; SOUZA, 2017), e caracterizando-se, assim, a sua principal diferença com relação à Economia Criativa.

Acompanhando essas perspectivas e por ser uma espécie de economia embasada no conhecimento, também é possível observar que, conceitualmente, ainda é feita certa correlação entre a Economia da Cultura e outras áreas como a Economia da Inovação ou a Economia do Conhecimento. Porém, isso não deveria ocorrer, pois tais áreas também possuem suas diferenças, uma vez que a Economia da Inovação e a Economia do Conhecimento são mais tradicionalistas e têm seu foco para as modificações que ocorrem com o conhecimento tecnológico ou científico em sociedade, além de objetivarem o que surge, como, por exemplo, produtos (CAIADO, 2011; FACHINELLI, D'ARISBO; MACIEL, 2014).

De maneira breve, a Economia Criativa apenas objetiva, com o conhecimento adquirido, gerar valor usando a criatividade e, consequentemente, apresentar e explorar novas formas de aquisição econômica (HOWKINS, 2001; DORION, et al., 2013). Dessa forma, ela acaba impulsionando a colaboração entre as pessoas, assim como novas práticas de mercado, como o consumo colaborativo, por exemplo (PAIXÃO; SOUZA, 2015).

Nesse processo, compondo uma dinâmica totalmente coesa, onde aquele que for o detentor das melhores ideias - mesmo que isso só aconteça em determinados casos - poderá vir a ser o mais poderoso em relação aos outros que só têm controle de equipamentos e de máquinas (HOWKINS, 2001; DORION, et al., 2013).

No que diz respeito à participação das comunidades e das organizações - que detêm governanças diversificadas, bem como de empresas de pequeno porte, que estejam inseridas na dinâmica criativa ou que incentivem a inclusão socioeconômica e o desenvolvimento sustentável -, a Economia Criativa reconhece que a criatividade contribui (e muito) para o seu desenvolvimento, principalmente se estiver focado nas pessoas dentro desses cenários. Algo que favorece também a sustentabilidade, o surgimento de empregos, a inclusão social e a diversidade cultural nesses ambientes (UNCTAD, 2010; LIMA, 2011; CLOSS; ROCHA-DE-OLIVEIRA, 2017).

\subsection{Indústrias, bens e serviços criativos}

Usualmente a compreensão que há com relação a determinados conceitos aponta que criatividade significa "[...] originar ideias, novas formas de olhar um problema que já existe ou olhar novas oportunidades. Inovação é o sucesso na exploração de novas ideias, é o processo que leva a novos produtos e serviços ou novas formas de fazer negócio" (GOLDENSTEIN, 2010, p. 8).

À vista disso, observa-se que esses são elementos imprescindíveis para a Economia Criativa, principalmente por essa ser uma área sistêmica, que, rotineiramente, se relaciona com novas tecnologias, com a cultura, com a economia e até mesmo com propostas mais sustentáveis (WACHOWICZ, 2011) para a criação e manutenção de bens e serviços. Essa área também suscita um grande espaço para comercialização e para a produção, onde, em sua maioria, destacam-se bens intangíveis, como propagandas, softwares, notícias, entre outros (HARTLEY, 2005; NICOLACI-DA-COSTA, 2014).

Conceitualmente em relação aos serviços criativos, Oliveira, Araujo e Silva (2013) mencionam que estes são os segmentos que possuem maiores quantidades de pessoas como: o design, a publicidade e a arquitetura, por exemplo. De tal forma que, no tocante às indústrias criativas, elas seriam as que em suas criações constroem-se sobre a criatividade e habilidades particulares de cada indivíduo, bem como o resultado que dispõe de uma sagacidade para gerar riquezas e empregos através da exploração dessas atividades (DCMS, 2001; ALMEIDA; TEIXEIRA; LUFT, 2014).

Assim, também é válida a ressalva de que as indústrias criativas por vezes se diferenciam das indústrias culturais, mediante os bens e serviços que cada uma produz (STONEMAN, 2010; OLIVEIRA; ARAUJO; SILVA, 2013); e que tanto a criatividade como a economia não são conceitos novos, mas que é exatamente a combinação entre esses elementos que resulta em algo criativo e inovador (HOWKINS, 2001; OLIVEIRA, ARAÚJO, SILVA, 2013). Sobre isso, e durante a análise dos respectivos dados dessa pesquisa, será possível observar, com maior clareza, o modo como esses conceitos interagem e se inserem no meio social. 
No entanto, para se ter uma breve noção de como a EC e seus empreendimentos atuam e impactam a economia nacional, pode-se usar como exemplo o ano de 2017, pois (a) no que compete a empregos formais, estavam em áreas criativas "[...] 366,4 mil trabalhadores formais, distribuídos entre Publicidade \& Marketing (150,8 mil), Arquitetura (94,8 mil), Design ( 76,1 mil) e Moda ( 44,7 mil)", (b) bem como houve crescimento de mercado para o setor de Gastronomia e profissões que buscavam aproximar cada vez mais as empresas e seus consumidores, como a área de Relações Públicas (FIRJAN, 2019, p. 19).

Isso não significa que não exista EC no mercado de trabalho informal ou que o uso de novas tecnologias neste segmento não tenha proporcionado aspectos negativos, mas que apesar disso a EC detém força na coletividade brasileira. Em uma breve reflexão, mas ainda tomando como exemplo o ano de 2017, foi perceptível que (c) a área de "Design registrou queda de $7,1 \%$ nos vínculos formais [...]", levando inúmeras pessoas à informalidade; já (d) as áreas criativas que envolvem consumo, mídias e inovações tecnológicas proporcionaram mudanças consideráveis em ocupações laborais tradicionais, transferindo-as para outros locais, como ocorreu com jornalistas e fotógrafos(as) e mantendo a EC (e) na área da cultura que compõe inúmeras indústrias criativas, como sendo a menor dentre as suas áreas criativas, pois nesse período e no mercado formal apenas "[...] contava com 64,9 mil profissionais [...] nos segmentos de Expressões Culturais (28,4 mil), Patrimônio e Artes (14,2 mil), Música (11,5 mil) e Artes Cênicas (10,8 mil)" (FIRJAN, 2019, p. 20-23).

\section{MÉTODO DA PESQUISA}

O presente estudo, dados os seus objetivos, foi moldado em uma metodologia qualitativa e quantitativa. Ou seja, quando procurou avaliar as conexões existentes entre determinadas variáveis (FLICK, 2013), usou-se a abordagem quantitativa e quando buscou interpretar os materiais obtidos para alcançar uma proximidade maior com o conhecimento existente na realidade dos fatos, usou-se a abordagem qualitativa (TAQUETTE, 2016).

Diante disso, seus objetivos denotaram aspectos descritivos e explicativos, uma vez que um estudo explicativo pode acabar sendo a continuação de outro descritivo, pois ao se identificar os elementos que compõem um dado fenômeno é igualmente necessário que esses elementos se encontrem muito bem descritos ao longo da pesquisa (GIL, 2007; GERHARDT; SILVEIRA, 2009).

Para a coleta de dados o procedimento adotado foi a análise bibliométrica, método que possibilita padronizar determinados processos, de modo a facilitar a organização e a mensuração dos materiais obtidos e que, por conseguinte, se encontram expostos em livros, monografias, artigos, teses, documentos, entre outros (BARBOSA et al. 2008; BARBOSA; QUINTANA, 2011; SOUZA et al., 2017). Entretanto, para complementar essas análises também se usou a análise de conteúdo, conjunto de técnicas que oportuniza que o pesquisador alcance a diversidade de significados existentes naquilo que foi coletado (ALVES-MAZZOTTI; GEWANDSZNAJDER, 1998; MINAYO, 2001; CRESWELL, 2007; FLICK, 2009; MOZZATO; GRZYBOVSKI, 2011).

Partindo-se dessas perspectivas, optou-se por trabalhar especificamente com artigos nacionais. Todavia, porque são internacionalmente percebidos como indicadores imparciais e de qualidade, o qual as Ciências em muito se usam, bem como se originam de uma variedade de instituições, o que impulsiona e mantém a diversidade de opiniões, temas e métodos de fácil acesso em meio público (OLIVEIRA, 2002).

No que se refere aos critérios de escolha dos periódicos, necessários à delimitação deste estudo, optou-se por utilizar a classificação dada pela CAPES (Coordenação de Aperfeiçoamento Pessoal de Nível Superior) para revistas e periódicos, no período de tempo de 2013 a 2016, pois essa instituição tanto possui um critério de maior impacto como de qualidade, que serve para separar determinados trabalhos dos que não percorreram processos rigorosos de admissão. Respectivamente, seguindo desde a classificação de maior nível, denominada A1, até um dentre os menores estratos denominado B3 (CAPES, 2015).

No entanto, outro posicionamento adotado durante a obtenção dos dados é que fossem retirados da análise de conteúdo os conceitos que não abordassem a EC, que conceituassem sobre como se caracteriza uma empresa do ramo ou que apenas explicassem como se deu o seu contexto histórico, pois o foco se encontrava em compreender como está área é definida, por se tratar de um tema ainda sem uma clara definição. Portanto, não se excluiu, com isso, os anos das definições obtidas, pois esse estudo não tem por objetivo excluir o seu desenvolvimento histórico, mas de se afastar daqueles conceitos que buscam explicar os acontecimentos para focar em como a Economia Criativa realmente é, bem como são suas diferentes nuances. Acompanhando esses aspectos, após a execução de algumas reuniões, se estruturaram os seguintes critérios e categorias, que, para facilitar a compreensão, foram ordenados com base no modelo conceitual de Kneippet al. (2013). Observa-se, então, no quadro a seguir. 
Quadro 1 - Critérios específicos da análise bibliométrica

\begin{tabular}{|l|l|l|}
\hline Categorias Analisadas & \multicolumn{1}{|c|}{ Elementos Analisados } & \multicolumn{1}{c|}{ Descrição } \\
\hline Característica da publicação & $\begin{array}{l}\text { a) Artigos nacionais que abordem sobre a EC } \\
\text { em pelo menos algum ponto da publicação } \\
\text { b) Palavras-chave }\end{array}$ & $\begin{array}{l}\text { a) Artigos nacionais no período de 2008-2018. } \\
\text { b) Palavras-chave: Economia Criativa, } \\
\text { Indústrias Criativas e Serviços Criativos. }\end{array}$ \\
\hline Dimensão metodológica & $\begin{array}{l}\text { c) Tipos de pesquisa } \\
\text { d) Abordagens das pesquisas } \\
\text { e) Natureza da pesquisa }\end{array}$ & $\begin{array}{l}\text { c) Teórica ou empírica (ou ambos). } \\
\text { d) Qualitativa ou quantitativa (ou ambos). } \\
\text { e) Descritiva e exploratória ou explicativa (ou } \\
\text { contendo mais de um desses elementos). }\end{array}$ \\
\hline Coleta dos dados & f) Forma de coleta & $\begin{array}{l}\text { f) Bibliométrica. } \\
\text { Em plataformas de acesso gratuito (aberto). } \\
\text { Sendo elas: Spell; Scielo e Plataforma CAPES. } \\
\text { Estrato Qualis CAPES: periódicos de A1 a B3. }\end{array}$ \\
\hline Análise dos dados coletados & g) Tipo de análise & $\begin{array}{l}\text { g) Análise de conteúdo. } \\
\text { h) Análise das citações (incluindo o quanto aquele artigo } \\
\text { foi citado dentro da base de dados e quais os principais } \\
\text { autores mencionados pelos artigos coletados). }\end{array}$ \\
\hline
\end{tabular}

Fonte: Adaptado baseado em Kneipp et al. (2013, p. 447).

Os meios escolhidos proporcionaram a coleta e análise de doze artigos, desde a introdução até a conclusão dos respectivos materiais, visto que esse estudo destacou aqueles que contivessem conceitos sobre EC em qualquer ponto da publicação. Desse modo, foi possível a observação de: (1) artigo obtido diretamente da base Scielo, (3) artigos da CAPES (com a ressalva de que os materiais coletados nessa base de dados eram redirecionados para a plataforma Scielo) e (8) artigos da base Spell (ver Quadro 2). Adiante é possível observar também os resultados obtidos com a efetuação dessas investigações acerca da temática.

\section{ANÁLISES E DISCUSSÕES}

Como a pesquisa bibliométrica é uma técnica que possibilita ao pesquisador analisar uma dada temática, estado ou tecnologia através de toda a produção científica existente. Achando-se ela armazenada em um determinado repositório de dados e fundamentada principalmente na contagem dos artigos, citações ou mesmo patentes referentes à finalidade do que se procura resolver (RAO, 1986; ZHU et al, 1999; SOARES et al, 2016), assim, obteve-se o seguinte cenário com a coleta de dados, ordenado com base no modelo conceitual de Almeida, Teixeira e Luft (2014).

Quadro 2 - Dos artigos coletados

\begin{tabular}{|c|c|c|c|c|c|c|c|c|}
\hline $\mathbf{N}^{\circ}$ & Autor(es) & $\begin{array}{l}\text { Bases de } \\
\text { Dados }\end{array}$ & Periódicos & $\begin{array}{l}\text { Estrato } \\
\text { Qualis } \\
\text { CAPES }\end{array}$ & $\begin{array}{c}\text { Tipo do } \\
\text { Artigo }\end{array}$ & $\begin{array}{l}\text { Natureza } \\
\text { da } \\
\text { Pesquisa }\end{array}$ & $\begin{array}{l}\text { Abordagem } \\
\text { da Pesquisa }\end{array}$ & Ano \\
\hline 1 & $\begin{array}{l}\text { LUGOBONI, Leonardo } \\
\text { F., et al.; ZITTEI, Marcus } \\
\text { Vinicius M.; MORAES, } \\
\text { Carlos Felipe M. de; } \\
\text { KAVESKI, Itzhak David S. }\end{array}$ & Spell & $\begin{array}{l}\text { Future Studies } \\
\text { Research Journal }\end{array}$ & B3 & $\begin{array}{l}\text { Pesquisa } \\
\text { empírica }\end{array}$ & $\begin{array}{l}\text { Exploratória } \\
\text { e descritiva }\end{array}$ & Qualitativa & 2014 \\
\hline 2 & $\begin{array}{l}\text { REYES JUNIOR, } \\
\text { Edgar; DIAS, Fagner; } \\
\text { GOMES, Renata. }\end{array}$ & Spell & $\begin{array}{l}\text { Revista Ciências } \\
\text { Administrativas }\end{array}$ & B2 & $\begin{array}{l}\text { Pesquisa } \\
\text { Empírica }\end{array}$ & Descritiva & $\begin{array}{l}\text { Qualitativa - } \\
\text { Quantitativa }\end{array}$ & 2018 \\
\hline 3 & $\begin{array}{l}\text { SANTOS, André Luis } \\
\text { N. dos; ANDRADE, } \\
\text { Richard N.; LUIZ, Yuri. }\end{array}$ & Spell & $\begin{array}{l}\text { Pensamento } \\
\text { \& Realidade }\end{array}$ & B3 & $\begin{array}{l}\text { Pesquisa } \\
\text { teórica - } \\
\text { empírica }\end{array}$ & $\begin{array}{l}\text { Exploratória } \\
\text { e descritiva }\end{array}$ & Qualitativa & 2017 \\
\hline 4 & $\begin{array}{l}\text { CASTRO, Elinajara } \\
\text { P.; CUTRIM, } \\
\text { KlautenysDellene G. }\end{array}$ & Spell & Revista Interface & B3 & $\begin{array}{l}\text { Pesquisa } \\
\text { teórica }\end{array}$ & Exploratória & Qualitativa & 2016 \\
\hline 5 & $\begin{array}{l}\text { RAMPAZZO, Nut L.; } \\
\text { RABONI, Pierre L.; MELLO, } \\
\text { Paula Roberta C. B. de. }\end{array}$ & Spell & $\begin{array}{l}\text { Revista Capital } \\
\text { Científico - } \\
\text { Eletrônica (RCCe) }\end{array}$ & B3 & $\begin{array}{l}\text { Pesquisa } \\
\text { empírica }\end{array}$ & Exploratória & Quantitativa & 2018 \\
\hline
\end{tabular}


Quadro 2 - Dos artigos coletados (continuação).

\begin{tabular}{|c|c|c|c|c|c|c|c|c|}
\hline $\mathbf{N}^{\circ}$ & Autor(es) & $\begin{array}{l}\text { Bases de } \\
\text { Dados }\end{array}$ & Periódicos & $\begin{array}{l}\text { Estrato } \\
\text { Qualis } \\
\text { CAPES }\end{array}$ & $\begin{array}{l}\text { Tipo do } \\
\text { Artigo }\end{array}$ & $\begin{array}{c}\text { Natureza } \\
\text { da } \\
\text { Pesquisa }\end{array}$ & $\begin{array}{l}\text { Abordagem } \\
\text { da Pesquisa }\end{array}$ & Ano \\
\hline 6 & $\begin{array}{l}\text { NUNES, B. S., et al.; } \\
\text { SCHREIBER, Dusan; } \\
\text { SCHMIDT, Serje; } \\
\text { MONTARDO, Sandra P. }\end{array}$ & Spell & $\begin{array}{l}\text { Revista Gestão } \\
\text { \& Planejamento }\end{array}$ & B2 & $\begin{array}{l}\text { Pesquisa } \\
\text { teórica - } \\
\text { empírica }\end{array}$ & Exploratória & Qualitativa & 2018 \\
\hline 7 & $\begin{array}{l}\text { BIANCHI, Caio G.; } \\
\text { BORINI, Felipe M. }\end{array}$ & Spell & $\begin{array}{l}\text { Pensamento } \\
\text { \& Realidade }\end{array}$ & B3 & $\begin{array}{l}\text { Pesquisa } \\
\text { empírica }\end{array}$ & $\begin{array}{l}\text { Explicativa } \\
\text { e descritiva }\end{array}$ & Quantitativa & 2013 \\
\hline 8 & $\begin{array}{l}\text { LIMA, Bruno C. C.; } \\
\text { LIMA, Tereza Cristina } \\
\text { B. de; CABRAL, } \\
\text { Augusto Cézar de A. }\end{array}$ & Spell & $\begin{array}{l}\text { Revista de } \\
\text { Carreiras e } \\
\text { Pessoas }\end{array}$ & B3 & $\begin{array}{l}\text { Pesquisa } \\
\text { teórica }\end{array}$ & Descritiva & Quantitativa & 2013 \\
\hline 9 & $\begin{array}{l}\text { NICOLACI-DA- } \\
\text { COSTA, Ana Maria. }\end{array}$ & CAPES & $\begin{array}{l}\text { Psicologia \& } \\
\text { Sociedade }\end{array}$ & $\mathrm{A} 2$ & $\begin{array}{l}\text { Pesquisa } \\
\text { teórica }\end{array}$ & Explicativa & Qualitativa & 2011 \\
\hline 10 & $\begin{array}{l}\text { BARBOSA, Jéfte } \\
\text { Fernando de A.; SANTOS, } \\
\text { Maria Salett T. }\end{array}$ & CAPES & $\begin{array}{l}\text { Revista Brasileira } \\
\text { de Ciências da } \\
\text { Comunicação } \\
\text { (Intercom) }\end{array}$ & $\mathrm{A} 2$ & $\begin{array}{l}\text { Pesquisa } \\
\text { teórico - } \\
\text { empírica }\end{array}$ & $\begin{array}{l}\text { Exploratória } \\
\text { e descritiva }\end{array}$ & Qualitativa & 2015 \\
\hline 11 & MARCHI, Leonardo De. & CAPES & $\begin{array}{l}\text { Revista Brasileira } \\
\text { de Ciências da } \\
\text { Comunicação } \\
\text { (Intercom) }\end{array}$ & A2 & $\begin{array}{l}\text { Pesquisa } \\
\text { teórica }\end{array}$ & Explicativa & Qualitativa & 2014 \\
\hline 12 & $\begin{array}{l}\text { PACHECO, Adriano P. de } \\
\text { C.; BENINI, Elcio Gustavo. }\end{array}$ & Scielo & $\begin{array}{l}\text { Revista de } \\
\text { Economia Política }\end{array}$ & $\mathrm{A} 1$ & $\begin{array}{l}\text { Pesquisa } \\
\text { teórica }\end{array}$ & Exploratória & Qualitativa & 2018 \\
\hline
\end{tabular}

Fonte: Adaptado baseado em Almeida, Teixeira e Luft (2014).

Dos artigos obtidos, a análise demonstrou que, em sua maioria, caracterizaram-se dentro dos estratos Qualis CAPES B2 e B3, bem como foram majoritariamente pesquisas qualitativas, apesar da existência de pesquisas quantitativas ou que se estruturaram em ambas as abordagens. No que se refere aos termos utilizados nas bases de dados, durante a coleta, (como se observa no Quadro 3) não foram encontrados artigos por meio do tema serviços criativos dentro do período estabelecido para a coleta (junho a outubro de 2019).

Além disso, alguns autores dos artigos analisados, ao conceituarem sobre a EC, ora utilizaram-se de outros teóricos para conceituá-la, ora utilizaram-se das próprias palavras para fazê-lo, mas sempre de acordo com os temas que estão sendo trabalhados em seus estudos, por exemplo, criatividade, cultura, entre outros. E em nenhum momento a pesquisa desconsidera essas formas de abordagens, visto que ambas são bastante relevantes.

Outro fator observável, com relação às publicações, é o tema ter sido trabalhado mais por homens do que por mulheres, caracterizando um perfil de 18 (67\%) homens e $9(33 \%)$ mulheres, o que apresenta que ainda há o que se "caminhar" para que se tenha uma participação mais efetiva de mulheres em estudos sobre a temática (ver Gráfico 1). Já com relação à quantidade de autores, foram mantidas, em sua maioria, artigos com no máximo dois ou três autores (ver Quadro 2).

Gráfico 1 - Perfil dos autores

Mulheres $\square$ Homens

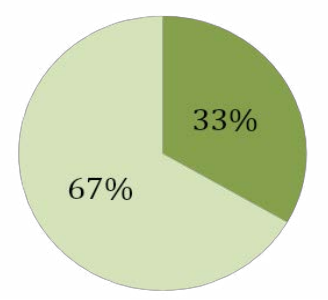

Fonte: Dados da pesquisa, 2019. 
Agora com relação aos principais autores mencionados pelas publicações quando trataram do conceito de Economia Criativa (considerando por publicação e não por vezes em que a pessoa foi citada em um único documento), destacou-se uma mulher, a pesquisadora Nicolaci-Da-Costa (2011), mencionada em quatro das doze publicações analisadas, enquanto que Miguez (2007) e a UNCTAD (2010) foram mencionados por dois estudos. Os demais só foram mencionados em uma única publicação, porém foram essencialmente relevantes para o desenvolvimento de cada pesquisa.

As publicações também se mantiveram como sendo fortemente realizadas no estado de São Paulo, no entanto, entre 2008 a 2018 o Nordeste também teve expressiva contribuição para os estudos sobre Economia Criativa com relação aos demais estados, com três publicações a respeito do tema (ver Gráfico 3). Além disso, por serem em sua maioria datados de 2018, os artigos obtidos comprovaram (conforme Quadro 3) que, até o presente momento, esse ainda é um tema recente e em ascensão.

Gráfico 3 - Origem geográfica dos artigos analisados.
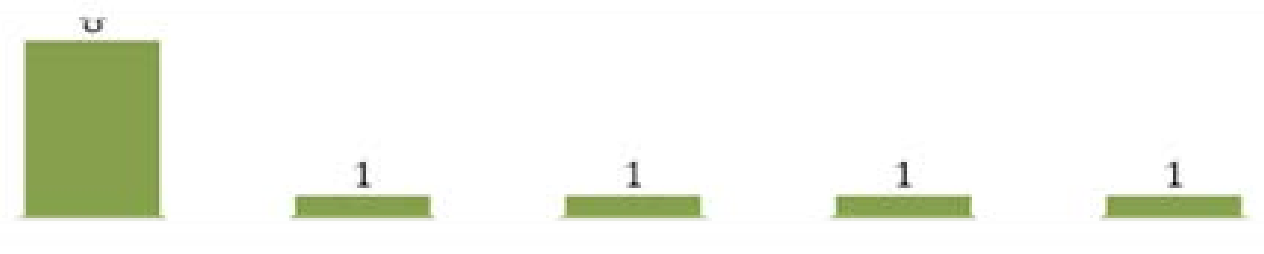

Fonte: Dados da pesquisa, 2019.

Em relação às palavras-chave de cada publicação, os artigos coletados trouxeram consigo uma diversidade de termos relacionados à temática como, por exemplo: desenvolvimento, inovação, criatividade e culturas populares. A análise de conteúdo foi essencial nesse processo, pois auxiliou a compreensão desses dados, uma vez que se iniciou desde os títulos (englobando as palavras-chave) até todo o texto do material coletado, como se pode constatar no quadro a seguir (BARDIN, 1977; FARIA; ALVES, 2016).

Quadro 3 - Dos artigos científicos coletados por área temática

\begin{tabular}{|c|c|c|c|}
\hline $\mathbf{N}^{\circ}$ & Por Área Temática & Palavras-Chave dos Artigos Coletados & $\begin{array}{l}\text { Palavra-Chave } \\
\text { Usada na Busca }\end{array}$ \\
\hline 1 & Administração & $\begin{array}{l}\text { "Economia Criativa; Tecnologia da Informação; Inovação; Capital Intelectual" } \\
\text { (LUGOBONI, et al., 2014, p. 153, tradução nossa). }\end{array}$ & Economia Criativa \\
\hline 2 & $\begin{array}{l}\text { Administração, Ciências } \\
\text { Contábeis e Turismo }\end{array}$ & $\begin{array}{l}\text { "Economia Criativa; Produtor Cultural; Redes Sociais; Relação Interpessoal" } \\
\text { (REYES JUNIOR; DIAS; GOMES, 2018, p. 1). }\end{array}$ & Economia Criativa \\
\hline 3 & Sociologia & $\begin{array}{l}\text { "Redes de Cultura; Arapiraca; Cidade Criativa". (SANTOS; ANDRADE; LUIZ, } \\
\text { 2017, p. 61). }\end{array}$ & Economia Criativa \\
\hline 4 & $\begin{array}{l}\text { Administração, Ciências } \\
\text { Contábeis, Economia e Turismo }\end{array}$ & $\begin{array}{l}\text { "Economia Criativa. Cultura. Museu. Comunidade. Turismo" (CASTRO; } \\
\text { CUTRIM, 2016, p. 49). }\end{array}$ & Economia Criativa \\
\hline 5 & $\begin{array}{l}\text { Administração, Ciências } \\
\text { Contábeis e Turismo }\end{array}$ & $\begin{array}{l}\text { "Economia Criativa; Porto Digital; Significado do Trabalho; Análise Fatorial" } \\
\text { (RAMPAZZO; RABONI; MELLO, 2018, p. 95). }\end{array}$ & Indústria Criativa \\
\hline 6 & Administração & $\begin{array}{l}\text { "Redes Sociais; Redes Estratégicas; Indústria Criativa; Plataformas Digitais" } \\
\text { (NUNES et al., 2018, p. 177). }\end{array}$ & Indústria Criativa \\
\hline 7 & Administração & $\begin{array}{l}\text { "Economia Criativa; ambiente institucional; exportação de serviços; gestão } \\
\text { internacional" (BIANCHI; BORINI, 2013, p. 1). }\end{array}$ & Indústria Criativa \\
\hline 8 & Administração & $\begin{array}{l}\text { "Estilos de Funcionamento, Mecanismos de Aprendizagem, Indústria Criativa" } \\
\text { (LIMA; LIMA; CABRAL, 2013, p. 2). }\end{array}$ & Indústria Criativa \\
\hline 9 & Psicologia & $\begin{array}{l}\text { “Jovens; Sucesso; Economia Criativa; Internet; Profissionalização” (NICOLACl- } \\
\text { DA-COSTA, 2011, p. 554). }\end{array}$ & Economia Criativa \\
\hline 10 & Ciências da Comunicação & $\begin{array}{l}\text { "Comunicação. Economia Criativa. Culturas Populares. Desenvolvimento } \\
\text { Local" (BARBOSA; SANTOS, 2015, p. 61). }\end{array}$ & Economia Criativa \\
\hline 11 & Ciências da Comunicação & $\begin{array}{l}\text { "Economia Criativa. Política Cultural. Ministério da Cultura. Secretaria de } \\
\text { Economia Criativa" (MARCHI, 2014, p. 193). }\end{array}$ & Economia Criativa \\
\hline 12 & Ciência Política & $\begin{array}{l}\text { "Economia Criativa; criatividade; desenvolvimento endógeno; Celso Furtado" } \\
\text { (PACHECO; BENINI, 2018, p. 324). }\end{array}$ & Economia Criativa \\
\hline
\end{tabular}

Fonte: Adaptado com base em Almeida, Teixeira e Luft (2014). 
Desse modo, com o auxílio da análise de conteúdo, tornou-se possível trazer de modo detalhado a convergência de conceitos e termos associados à Economia Criativa. Cabe ressaltar com isso que, através dessa análise, foi possível observar quais as palavras mais citadas nos conceitos apresentados pelos autores das publicações (ver Quadro 4). É importante destacar que, nessa etapa, a pesquisa se pautou em classes analíticas livres, visto que se caracterizam por serem categorias que não foram estabelecidas no início do estudo, mas que se desenvolveram ao longo do caminho percorrido durante as análises dos dados (BARDIN, 1977; FARIA; ALVES, 2016); bem como se observa a seguir na identificação da convergência de conceitos com base na frequência de palavras mais mencionadas pelos autores das publicações (ora com as próprias palavras, ora com as palavras de terceiros).

Quadro 4 - Das palavras mais mencionadas nos artigos por ordem de frequência

\begin{tabular}{|l|c|l|c|}
\hline \multicolumn{1}{|c|}{ Palavras } & Quantidade & \multicolumn{1}{c|}{ Palavras } & Quantidade \\
\hline Desenvolvimento & 22 & Fenômeno & 3 \\
\hline Cultura & 19 & Mudanças & 3 \\
\hline Criatividade & 15 & Habilidade & 3 \\
\hline Indústrias criativas & 12 & Sustentável & 3 \\
\hline Diversidade & 8 & Talento & 3 \\
\hline Tecnologia & 7 & Conhecimento & 3 \\
\hline Comunidade & 3 & Sustentabilidade & 2 \\
\hline Propriedade intelectual & 3 & Tolerância & 2 \\
\hline Estratégia & 3 & Reconhecimento & 2 \\
\hline Inovação & 3 & & \\
\hline
\end{tabular}

Fonte: Elaborado pelas autoras (2019).

Guiando-se ainda pela frequência de palavras, observou-se que a Economia Criativa foi compreendida principalmente dentro de quatro segmentos: desenvolvimento, cultura, criatividade e indústrias criativas. Tais termos se destacaram mais do que tecnologia ou inovação, por exemplo. Nesse processo, observou-se que o termo desenvolvimento surgiu como sendo a principal característica dessa área, pois a Economia Criativa propicia o progresso dos setores que dela se utilizam. Inclusive, é mencionado no artigo $n^{\circ} 2$ que este é um conceito ainda em evolução, no entanto, por ser estruturado em ativos criativos, amplia o desenvolvimento econômico (UNCTAD, 2012; REYES JUNIOR; DIAS; GOMES, 2018).

Em relação ao artigo $n^{\circ} 4$, este desenvolvimento é apresentado como principal aliado do turismo cultural e do crescimento de determinadas localidades que dependem desse turismo, pois é graças a essa parceria que se potencializam meios de produção e venda dos produtos comercializados nessas regiões (CASTRO; CUTRIM, 2016).

Além disso, no que compete ao desenvolvimento, esta é uma área também vista como meio impulsionador da geração de empregos e renda. No artigo $n^{\circ} 6$, inclusive, os autores focam nesse potencial (de desenvolvimento), apresentando-o como um meio gerador de renda, apesar das dificuldades existentes com relação à criação de políticas públicas para a área (KON, 2016; NUNES et al., 2018).

Portanto, a Economia Criativa também é vista como propiciadora de mudanças sociopolíticas, bem como educacionais, conforme artigo $n^{\circ} 7$ (BLYTHE, 2001; BIANCHI; BORINI, 2013). 0 artigo $n^{\circ} 8$ reforçou essa perspectiva, principalmente porque a apresentou como algo que, além das indústrias criativas, engloba e provoca mudanças profundas na sociedade, como transformações socioeducativas, organizacionais e políticas. (REIS, 2008; LIMA; LIMA; CABRAL, 2013). Já o artigo $n^{\circ} 5$ mencionou que a EC abrange as indústrias criativas e outras áreas da economia, propiciando mudanças sociopolíticas, econômicas, educacionais e organizacionais (REIS, 2011; RAMPAZZO; RABONI; MELLO, 2018).

Com relação ao termo cultura, observou-se que a cultura dentro dessa temática está atrelada à identidade cultural dos sujeitos, bem como também a cultura popular, ao desenvolvimento cultural e até mesmo a Economia da Cultura. No artigo $n^{\circ} 3$, por exemplo, os autores fazem essa correlação determinando que a Economia Criativa seja um conceito que advém da Economia da Cultura, porém, sofrendo influências dos antigos conceitos que deram origem às indústrias criativas. Além disso, é através dela que as várias localidades passaram a valorizar suas singularidades e, por conseguinte, a identidade cultural dos sujeitos, trazendo crescimento para essas regiões (MACHADO, 1988; SANTOS; ANDRADE; LUIZ, 2017).

Entretanto, com as análises se tornou mais evidente o quanto a criatividade também é um elemento imprescindível para esse conceito econômico, por essa área ser estruturada basicamente no uso das novas tecnologias da informação, como bem destaca o artigo no 1 (NICOLACI-DA-COSTA, 2011; LUGOBONI; ZITTEI; MORAES; KAVESKI, 2014), além 
de também ser vista como um setor econômico de produtos ou serviços, essencialmente moldados na criatividade, conforme artigo $n^{\circ} 10$ (COHEN et al. 2008; UNESCO, 2008; BARBOSA; SANTOS, 2015).

No artigo $n^{\circ} 9$ a criatividade é destacada novamente, pois a concepção trazida com relação à EC é de que ela articula seu conceito à tolerância, talento e tecnologia, bem como também dedica "[...] à criatividade o papel de sua força motriz e às tecnologias digitais, principalmente à Internet, o Status de sua condição de emergência bem como de sua infraestrutura" (NICOLACI-DA-COSTA, 2011, p. 554). Para o artigo $n^{\circ} 7$, por exemplo, a Economia Criativa, através do uso da criatividade, é conceituada como uma economia que foi capaz de propiciar novas formas de se vivenciar o capitalismo nas sociedades, principalmente porque os meios tradicionais e de massificação do processo produtivo cederam espaço para a influência do conhecimento e da criatividade no processo de criação e produção de itens únicos, geralmente, personalizados e, por conseguinte, de alto valor agregado com relação aos demais (BENDASSOLLI et al., 2008; BIANCHI; BORINI, 2013).

A diversidade, evidentemente, se insere em boa parcela dessas perspectivas, pois através da diversidade de habilidades individuais, talentos e conhecimentos (entre outros fatores) é que a Economia Criativa se desenvolve. Inclusive, é ainda no artigo $\mathrm{n}^{\circ} 7$ que o seu entendimento enquanto economia também reside em três elementos: inovação (tecnologia), mão de obra (talento) e diversidade (tolerância). Nele, a diversidade presente na área é, na realidade, a tolerância às minorias, uma vez que ela sofre influências do modo como a sociedade aceita e percebe essas minorias (FLORIDA, 2003; BIANCHI; BORINI, 2013).

Apesar de a diversidade nessa área ser um assunto focado principalmente no talento, habilidades individuais e na propriedade intelectual das pessoas, quando se analisou cada artigo, também foi possível compreender que a EC se estrutura especialmente na individualidade criativa e cultural de cada sujeito para gerar renda, apesar de não impedir a colaboração entre as pessoas.

Como pode ser visto, no trecho a seguir, retirado do artigo $n^{0} 12$ :

Esse reconhecimento da criatividade que (in)surge a partir das identidades locais, do povo, fortalece a ideia de que a EC brasileira deve, a fortiori, ser entendida como aquela introjeta de simbologia, considerando a imensidão de sua diversidade cultural, a exemplo do escopo tratado no plano da extinta Secretaria da Economia Criativa, do Ministério da Cultura. Ao mesmo tempo, condena veementemente qualquer apropriação ou desvirtuação que possa deslocá-la para lógica dos meios, como tratada na própria Indústria Cultural (PACHECO; BENINI, 2018, p. 333).

Outros pontos que chamaram bastante atenção acerca da Economia Criativa foram: sustentabilidade, mudanças, estratégia e diversidade. Por exemplo, no artigo $n^{\circ} 11$, a publicação destacou que há nessa área o interesse pela proteção ao meio ambiente, bem como a valorização da expressão de culturas regionais (MARCHI, 2014). O artigo $\mathrm{n}^{\circ} 4$, inclusive, reforçou essa compreensão, quando foi mencionado que em conjunto com a Economia da Cultura constitui a Economia Criativa como um diferencial, onde há a busca pelo desenvolvimento tanto colaborativo como sustentável e participativo (NASCIMENTO; FREDER; MARCHETTE, 2013; CASTRO; CUTRIM, 2016).

\section{CONSIDERAÇÕES FINAIS}

A principal contribuição deste trabalho é possibilitar que futuros pesquisadores possam se utilizar dessa informação em diversas abordagens e, por conseguinte, ao saberem quais são as principais referências e definições utilizadas sobre Economia Criativa, consolidar o uso do conceito em seus estudos.

Assim, também se compreendeu que a utilização tanto da análise bibliométrica como da análise de conteúdo reforçou a importância que há em estudar trabalhos anteriormente produzidos, principalmente visto que eles são essenciais para o desenvolvimento e consolidação de determinados campos das Ciências em razão de possibilitarem a identificação de lacunas e, consequentemente, a construção de novas perspectivas e parâmetros que em um dado momento beneficiarão a coletividade (KNEIPP et al., 2013; ALMEIDA; TEIXEIRA; LUFT, 2014).

A pesquisa demonstrou também que há mais conceitos convergentes do que divergentes sobre o assunto, concluindo que a maioria das pesquisas analisadas se concentrou especialmente nos seguintes aspectos: desenvolvimento, cultura, criatividade e indústrias criativas. Então, até o presente momento, por meio dos saberes apresentados aqui, a Economia Criativa é: uma área ou segmento da economia, que permite o desenvolvimento econômico e/ou de diversos setores que se usam da cultura e principalmente da criatividade (das pessoas, de indústrias e/ou setores criativos) para a geração de renda para todas as classes sociais.

Ademais, diferente de outros segmentos econômicos, observou-se que, por exemplo, a cultura nessa área não vem como ponto central e tão pouco o conhecimento, mesmo que a integre, mas o seu foco ainda é a criatividade; visto que a cultura e o conhecimento (tão importantes) estão ali enraizados nos saberes e na identidade cultural das pessoas que se usam da criatividade e dos seus múltiplos saberes para estruturarem os seus negócios.

No entanto, isso não quer dizer que a EC não tenha pontos negativos ou que ela não se encontre vulnerável também à informalidade, algo tão presente no trabalho brasileiro. O que se compreende é que, enquanto conceito, 
ela se estrutura essencialmente nessas perspectivas de desenvolvimento, criatividade, cultura e indústrias criativas; e, por consequência, também possibilita, ainda que lentamente, o surgimento de políticas públicas e propostas socioeducativas e/ou políticas voltadas para essa área em níveis federal, estadual ou municipal.

Outro achado da pesquisa, que merece destaque, é que a Economia Criativa também foi relacionada com os termos: sustentabilidade, mudanças, estratégia e diversidade. Portanto, acompanhando essas perspectivas, a Economia Criativa é na prática uma área que impulsiona o desenvolvimento econômico, social e educacional de várias regiões, por meio do uso da criatividade e da cultura dos indivíduos que dela se utilizam, e também em prol de um crescimento mais sustentável e colaborativo.

No tocante à limitação do presente estudo, no que se refere à quantidade de vezes que um dado artigo foi citado, existe a possibilidade de que as bases de dados (Scielo, Spell e CAPES) só tenham conhecimento sobre os artigos citados por outros autores que se encontram publicados na própria plataforma, ou seja, os seus valores não transmitem a quantidade real de vezes que tal autor(a) foi citado(a). Como exemplo desse problema, observou-se o que ocorreu nas plataformas Scielo e Spell, onde, por vezes, se constava que o artigo não havia sido mencionado em outros trabalhos, mas quando a coleta de dados era efetuada dentro da base do Google Acadêmico, observou-se que um dado artigo foi citado diversas vezes por outras pessoas.

Outro aspecto deste estudo é que, ao serem realizadas buscas no Periódico CAPES, observou-se que o artigo era redirecionado em algumas vezes para o banco de dados da Scielo, em outras palavras, a pesquisa foi realizada no banco de dados da CAPES, mas o artigo selecionado estava indexado ao site da Scielo. Por fim, como sugestões para trabalhos futuros também se sugere que sejam analisados periódicos internacionais, como possibilidade de ser realizada uma comparação para compreender a maneira que outros pesquisadores entendem e empregam o conceito de Economia Criativa, bem como, suas aproximações e distâncias.

\section{REFERÊNCIAS}

ALMEIDA, A. S. de; TEIXEIRA, R.M.; LUFT, M. C. M. Mapeando a Produção Científica Sobre Economia Criativa em Periódicos Nacionais e Internacionais de 2000 a 2013. Revista Pensamento Contemporâneo em Administração (RPCA), Rio de Janeiro, v. 8, n4, out./set. 2014, p. 23-47.

ALMEIDA, A. S. de; TEIXEIRA, R. M. A Criação de Negócios de Micro e Pequeno Porte da Economia Criativa. Revista Eletrônica de Ciência Administrativa (RECADM), IBEPES, Curitiba - PR, v. 15, n. 2, p. 74-89, 2016.

BARBOSA, J. F. de A.; SANTOS, M. S. T. Comunicação, Economia Criativa e desenvolvimento local: a experiência do 'Núcleo de Comunicação Bombando Cidadania'. Intercom, Rev. Bras. Ciênc. Comun., São Paulo, v. 38, n. 2, p. 61-80, 2015.

BIANCHI, C. G.; BORINI, F. M. Internacionalização da indústria criativa: o impacto do ambiente institucional. Pensamento \& Realidade, [s. ], v. 28, n. 4, p. 1-20, 2013.

CASTRO, E. P.; CUTRIM, K. D. G. Economia Criativa no Museu Casa da Festa em São Luis - MA: Estratégias, Inovações e o Desenvolvimento do Turismo Cultural. Interface - Revista do Centro de Ciências Sociais Aplicadas, [s. ], v. 13, n. 2, p. 49-63, 2016.

Coordenação de Aperfeiçoamento de Pessoal de Nível Superior Ministério da Educação - CAPES. Critérios de classificação Qualis - Ensino. Brasília: Ministério da Educação, [2021].

CARVALHAL, F.; MUZZIO, H. Economia Criativa e Liderança Criativa: uma associação (im)possível? REAd, Porto Alegre, v. 82, n.3, p. 659-688, set./dez. 2015.

CLOSS, L.; OLIVEIRA, S. R. de. Economia Criativa e Territórios Usados: um debate baseado nas contribuições de Milton Santos. Cadernos EBAPE, Rio de Janeiro, v. 15, n 2, p. 349-363, 2017.

COSTA, W. F. et al. Uso de Instrumentos de Coleta de Dados em Pesquisa Qualitativa: um estudo em produções científicas de turismo. Revista Turismo: Visão e Ação - Eletrônico, Itajaí - SC, v. 20, n 1,p.2-28, jan./abr. 2018.

COIMBRA, K. E. R.; MORAIS, M. D. C. de. Eleições presidenciais 2018 e gestão Bolsonaro: o não lugar da cultura. Argumentum, [s. I..], v. 11, n. 3, p. 140-156, 2019.

DORION, E. C. H., et al. Criação de Conhecimento: Economia Criativa Versus Gestão Tradicional. Revista da Faculdade de Administração e Economia (ReFAE), São Paulo, v. 5, n 1, p. 2-27, 2013. 
FARIA, A. H. P. de; ALVES, D. F. C. Caderno de Geografia: análise bibliométrica, espacial e de conteúdo do acervo de 1990 a 2016. Caderno de Geografia, Belo Horizonte, v. 26, n 1, p.1-19, 2016.

FEDERAÇÃO DAS INDÚSTRIAS DO ESTADO DO RIO DE JANEIRO (FIRJAN). Mapeamento da Indústria Criativa no Brasil. Rio de Janeiro: FIRJAN, 2014.

FEDERAÇÃO DAS INDÚSTRIAS DO ESTADO DO RIO DE JANEIRO (FIRJAN). Mapeamento da Indústria Criativa no Brasil: diagnósticos e mapeamentos setoriais. Rio de Janeiro: FIRJAN, 2016.

FEDERAÇÃO DAS INDÚSTRIAS DO ESTADO DO RIO DE JANEIRO (FIRJAN). Mapeamento da Indústria Criativa no Brasil. Rio de Janeiro: FIRJAN, 2019.

FLICK, U. Introdução à Metodologia de Pesquisa: um guia para iniciantes. Porto Alegre- RS: Editora Penso, 2013, 256 p.

GERHARDT, T. E.; SILVEIRA, D. T. Métodos de pesquisa. Porto Alegre: Editora da UFRGS,, 2009.

GOLDENSTEIN, L. Economia Criativa. São Paulo: UNICAMP, 2010.

JESUS, D. S. V. de. Economia Criativa, Desenvolvimento e Sustentabilidade: o caso do Rio de Janeiro. Guaju - Revista Brasileira de Desenvolvimento Territorial Sustentável, Matinhos - Paraná , v. 3, n. 2, p. 65-80, jul./dez. 2017.

KNEIPP, J. M. et al.Análise bibliométrica da produção científica da revista de Administração da UFSM: em busca de novas perspectivas e desafios. Rev. Adm. UFSM, Santa Maria, Santa Maria, v. 6, n. 2, p. 443-458, jun. 2013.

LIMA, B. C. C.; LIMA, T. C. B.; CABRAL, A. C. A. Estilos de Funcionamento, Mecanismos de Aprendizagem, Indústria Criativa. Revista de Carreiras e Pessoas, São Paulo, v. 3, n. 3, p. 2-18, set./dez. 2013.

LUGOBONI, L. F. et al. Creative Economy as appliedtolnformationTechnology (IT) Companies. Future Studies Research Journal, São Paulo, v.6, n.1, p.154-173, jan./jun. 2014.

MARCHI, L. de. Análise do Plano da Secretaria da Economia Criativa e as transformações na relação entre Estado e cultura no Brasil. Intercom RBCC, São Paulo, v.37, n.1, p. 193-215, jan./jun. 2014.

MARCHI, L. Construindo um conceito neodesenvolvimentista de Economia Criativa no Brasil: Política cultural na era do novo MinC. Novos Olhares, [s. I.], v. 2, n. 2, p. 37-48, 2013.

MOZZATO, A. R.; GRZYBOVSKI, D. Análise de Conteúdo Como Técnica de Análise de Dados Qualitativos no Campo da Administração: potencial e desafios. Revista de Administração Contemporânea (RAC), Curitiba, v. 15, n.4, p. 731-747, jul./ago. 2011.

MARÇAL, M. C. C.; SANTOS, J. I. A. S. As potencialidades e os limites presentes na Economia Criativa de Pernambuco no período de 2013-2016. Pensamento \& Realidade, São Paulo, v. 33, n. 2, p. 86-106, abr./jun. 2018.

NICOLACI-DA-COSTA, A M. Economia Criativa, a Web 2.0 e o vírus da exposição de talentos. Psicologia: Ciência e Profissão, [s. I.], v. 34, n.4, p. 955-970, 2014.

NICOLACI-DA-COSTA, A. M. O talento jovem, a internet e o mercado de trabalho da "Economia Criativa". Psicol. Soc., Florianópolis, v. 23, n. 3, p. 554-563, 2011.

NUNES, B. S. et al. Redes estratégicas mediadas por plataformas digitais na indústria criativa: proposta de um quadro teórico. Revista Gestão \& Planejamento, Salvador, v. 19, n. 1, p. 177-190, 2018.

NUSSBAUMER, G. M. (org.). Teorias \& políticas da cultura: visões multidisciplinares. Salvador: EDUFBA, 2007.

OLIVEIRA, J. M. de; ARAUJO, B. C. de; SILVA, L. V. Panorama da Economia Criativa no Brasil. Texto para Discussão 1880. Brasília: Instituto de Pesquisa Econômica Aplicada (IPEA), 2013.

OLIVEIRA, P. G. et al. Economia criativa na produção científica brasileira em administração: mapeamento bibliométrico 
nas bases Anpad, Capes e Spell. Revista Geintec-Gestaolnovacao e Tecnologias, São Cristóvão/SE, v. 6, n. 1, p. 2966-2981, 2016.

OLIVEIRA, M. C. Análise dos Periódicos Brasileiros de Contabilidade. Revista Contabilidade \& Finanças - USP, São Paulo, n.29, p. 68-86, maio/ago. 2002.

PAIXÃO, C. R.; SOUZA, R. P. L. de. Consumo Colaborativo: tendência de construção de conhecimento e negócios no mercado digital de produtos usados. Perspectivas em Gestão \& Conhecimento, João Pessoa, v. 5, n. 2, p. 170-185, jul./dez. 2015.

PACHECO, A. P. de C.; BENINI, E. G. A. Economia Criativa em época de crise: o desenvolvimento endógeno brasileiro na obra de Celso Furtado. Brasil. J. Polit. Econ., São Paulo, v. 38, n. 2, p. 324-337, 2018.

RAMPAZZO, N. L.; RABONI, P. L.; MELLO, P. R. C. B. O Significado do Trabalho na Indústria Criativa: Um Estudo no Porto Digital do Recife (Brasil). Revista Capital Científico - Eletrônica, Guarapuava - PR, v. 16, n. 3, p. 95-108, 2018.

REYES JUNIOR, E.; DIAS, F.; GOMES, R. A. Economia Criativa sob a Ótica das Redes Sociais dos Produtores Culturais de Brasília. Revista Ciências Administrativas, Fortaleza, v. 24, n. 3, p. 1-15, 2018.

RELATÓRIO de Economia Criativa 2010: Economia Criativa uma opção de desenvolvimento Brasília: Secretaria da Economia Criativa/Minc; São Paulo: Itaú Cultural, 2012. 424p.

SANTOS, A. L. N. D.; ANDRADE, R. N.; LUIZ, Y. Por uma cartografia das redes e tramas da cultura Arapiraquense: diálogos sobre a ressignificação dos territórios de fronteira a partir de políticas de identidade e Economia Criativa, um relato de pesquisa. Pensamento \& Realidade, [s. I.], v. 32, n. 4, p. 61-73, 2017.

SILVA, F. A. B.; VIEIRA, M. P.; FRANCO, B. L. A Economia Criativa sob medida: conceitos e dinamismo das classes criativas. Texto para Discussão2493. Brasília: Instituto de Pesquisa Econômica Aplicada (IPEA), 2019.

SERRA, N.; FERNANDEZ, R S. Economia Criativa: da discussão do conceito à formulação de políticas públicas. Revista de Administração e Inovação (RAI), São Paulo, v. 11, n. 4, p. 355-372, out./dez. 2014.

SILVA, A D. da. O processo regulador na [Re]conversão de um arranjo produtivo local: o caso do Portomídia Centro de Empreendedorismo e Tecnologia da Economia Criativa. 2014. Dissertação (Mestrado em Administração) - Pós-Graduação em Administração, Universidade Federal de Pernambuco, 2014.

SOARES, P, B. et al. Análise bibliométrica da produção científica brasileira sobre tecnologia de construção e edificações na base de dados Web of Science. Ambiente Construído, Porto Alegre, v.16, n.1, p. 175-185, 2016.

SOUZA, R. M. F. de; et al.Análise bibliométrica dos artigos científicos em finanças publicados na Revista de Administração de Empresas (RAE) da FGV/SP, no Período de 2006 a 2016. Administração: Ensino e Pesquisa, Rio de Janeiro, v.18, n.3, p. 489-517, set./dez. 2017.

SOUZA, I. A. J. de. A Economia Criativa do Mundo Antigo. Diálogo com a Economia Criativa, Rio de Janeiro, v. 2, n.4, p. 26-38, jan./abr. 2017.

TAQUETTE, S. R. Análises de dados de pesquisa qualitativa em saúde. In: CONGRESSO IBERO-AMERICANO EM INVESTIGAÇÃO QUALITATIVA, 5.; INTERNATIONAL SYMPOSIUM ON QUALITATIVE RESEARCH, 1., 2016, Porto - Portugal. Anais [...]. Porto - Portugal: UFMS, 2016. p1-18.

CREATIVE EconomyProgramme. United NationsConferenceon Trade and Development. Genebra, Suíça, [2021]. Link. Acesso em:10 ago. 2021.

WACHOWICZ, M.; SILVA, R. O. C. E. Direito Autoral e Economia Criativa: a construção de uma economia preocupada com a criatividade. Liinc em Revista, Rio de Janeiro, v. 7, n.2, p. 556-572, out. 2011. 


\section{Contato:}

Emmanuelle Lopes de Almeida

E-mail: emmalopes2012@hotmail.com

Pâmela Karolina Dias

E-mail: pamela.dias@ufpe.br 